\title{
THE IMPACT OF CERTAIN ANTHROPOMETRIC DIMENSIONS ON THE REALIZATION OF MOTOR ABILITIES IN KARATE ATHLETES
}

\author{
Shkelzen Shalja', Visar Ganiu², Zorica Stankovska², Žarko Kostovski ${ }^{1}$ \\ 'Cyril and Methodius University, Faculty of Physical Education, Sport and Health, Skopje, Macedonia \\ ${ }^{2}$ Cyril and Methodius University, Faculty of Pedagogy, St. Kliment Ohridski, Skopje, Macedonia
}

Original scientific paper

\begin{abstract}
The research was conducted on 37 senior karate athletes' seniors, males, at the age of 18 to 30, competitors of international rank. They are potential members of the Kosovo national team. Two test batteries were used on the sample of the respondents: 5 anthropometric variables as a predictor system and 13 basic motor variables as a criterion system. From previous studies it can be concluded that the longitudinal dimensionality of the skeleton and motor abilities, in particular, speed, explosive force, as well as coordination of movement play an important role in karate sport, especially for the competitors who participate in the discipline kumite.

The research was conducted in order to determine the impact of the predictor system of variables on the success of the realization of the criterion variables. By applying Linear Regression Analysis, the connection of the predictors with certain motor tests was determined, i.e. their prediction was determined.
\end{abstract}

Key words: Karate, Anthropometric, Motor.

\section{INTRODUCTION}

Modern karate competitions consist of two individually important karate disciplines kumite and kata (Elena Soklevska Ilievski, Egzon Shala \& Zarko Kostovski., 2018). Due to the fact that they are based on different selections of movement techniques (kinematic and kinetic parameters), they differ in their anthropometric and physical performance. Kumite matches are characterized by a complex technical structure and specific abilities of competitors in the field of combined attack techniques (Chaabčne, H., Franchini, E., Miarka, B., Amin, SM, Mkaouer, B., \& Chamari, K. 2014). The dynamics during the fight and the high frequency of movements by the karate athletes require having a high level of motor and functional abilities with special emphasis on speed, power and coordination. (Kostovski, 1996). Success in any sport, and thus in karate, depends on the interaction of several factors: techniques, tactics, speed of decision-making and mental abilities, but of course it also depends on the physiological characteristics of the karate athlete. (Boško Zaborski, Kastriot Šakiri, Nina Đukanović, \& Žarko Kostovski, 2015). Karate belongs to the group of acyclic poly-structural sports which are dominated by acyclic movements, movements that are performed in direct contact with the opponent (in kumite) and with an imaginary opponent (kata). Karate as a sport discipline has a positive effect on the transformation of the psychosomatic system more than any other sports. Through its practice, this sport aims to promote the psychophysical energy of the athlete (Kostovski, 2004). From previous studies it can be concluded that the longitudinal dimensionality of the skeleton and motor abilities, primarily, speed, explosive force, as well as coordination of movement, play an important role in karate sport, especially for competitors who participate in the discipline kumite. Based on this factor, the aim of this study is to investigate the relationship between certain motor abilities and anthropometric dimensions, in karate competitors, at the age of 18-30, who are active competitors in Kosovo and have achieved results in national and international competitions.

\section{MATERIALS AND METHODS}

The research was conducted with 37 male karate athletes, at the age of 18-30. They have a longer sports career, active athletes and competitors in the senior and U-21 category. In their sports career, they are participants in many competitions of international rank, and some of them are medal winners. Two test batteries were used on the sample of the respondents: 5 anthropometric variables as a predictor system, and 13 motor variables as a criterion system. The applied anthropometric variables were measured according to the IBP (International Biological Program) 1. Body weight (APESHA), 2. Body height (ALART), Leg length (AGJAKE) 4. Arm length (AGJASH) 5. Shoulder width ( AGJAKR).

The motor variables as a criterion system applied in this research were measured according to the methodology of Metikoš, D., Port, F., Hofman, E., Pintar, Z., Oreb, G. (1998) as follows: 1. Running at $30 \mathrm{~m}$ (MVR30M), 2. Running at $60 \mathrm{~m}$ (MVR60M), 3. Running at $100 \mathrm{~m}$ (MVR100M), 4. 
Hand taping (MTAPDOR), 5. Foot taping (MTAPMK), 6. Figure 8 running (MTETR), 7. Steps aside (MHAPAN), 8. Rectangle (MKATKEN), 9. Impact block (MBLOKGO), 10. Long jump (MKGJV), 11. High jump (MKVLART), 12. Throwing medicine ball from chest (MHMBSH) 13. Throwing Medical Ball from Lying (MHMBGJ).

\section{Statistical methods for data processing}

In order to determine the relationship between the applied variables, the basic descriptive parameters were used, as follows: Mean - arithmetic mean, Std.Dev. - standard deviation, which should be at least 1/3 of the value of the arithmetic mean, Min. - minimum score, Max. - maximum score, Skew. - symmetry of the result distribution, i.e. the protrusion of the result distribution curve, and Kurt. - roundness of the distribution of the results, which will simultaneously determine the homogeneity of the test results.

The assessment of the participation of the predictor system of variables above the criteria was confirmed with the help of Linear Regression Analysis. Also the coefficients of Multiple Correlation (RO), coefficient of determination (DELTA), partial regression coefficient (BETA) and $F$ test to check the hypotheses of multiple correlations were calculated.

\section{RESULTS AND DISCUSSION}

Table 1 shows data related to the anthropometric characteristics of karate athletes $(N=37)$ from the measurement. Analyzing the data from the basic descriptive statistical parameters of the anthropometric variables in the respondents, it can be concluded that the deviation from the normal values of the standard deviation is not found in any variable. The range of the lower and upper limit in which the results move (Min. And Max.) is expected and logical. Statistically significant deviation of the symmetry of the result values (Skew) was not registered in any of the variables. The degree of curvature at the top of the curve (Kurt) is platycurtic, indicating that all of the values obtained are less than \pm 3 and are within the recommended range. From them it can be concluded that this is a relatively homogeneous group of respondents. Comparing the obtained values with similar researches, it can be said that the values are within the normal range (Fazliu, 2006 and Berisha, 2002).

Table 1. Basic settings of anthropometric statistics

\begin{tabular}{|c|c|c|c|c|c|c|c|}
\hline & $N$ & Min & Max & Mean & Std. D & Skew & Kurt \\
\hline APESHA & 37 & 59.4 & 89.8 & 72.15 & 7.68 & 0.46 & 0.16 \\
\hline ALART & 37 & 166 & 189 & 178.5 & 5.40 & -0.42 & -0.05 \\
\hline AGJATKE & 37 & 90.0 & 110 & 99.1 & 5.08 & 0.10 & -0.42 \\
\hline AGJASHP & 37 & 25.0 & 29.5 & 27.2 & 0.89 & 0.43 & 0.83 \\
\hline AGJAKR & 37 & 72.0 & 93.0 & 80.5 & 4.73 & 0.43 & 0.33 \\
\hline
\end{tabular}

Legend: N-number of respondents, Min-minimum score, Max-maximum score, Std.D-standard deviation, Skew- coefficient of asymmetry of results and Kurt-coefficient of elongation of results

Table 2 shows the results of the basic descriptive statistical parameters obtained from the assessment of the motor abilities in the group of respondents. From them it can be noticed that in all applied variables, the standard deviation (Std.Dev) is within the limits of normal values, i.e. they are less than $1 / 3$ of the arithmetic means. Deviation from the normal values of the standard deviation (Std.Dev) is not noticeable in any of the measured variables. The maximum and minimum values are expected and do not indicate the existence of extreme values, which in turn indicates that the grouping of the results mainly revolves around their own arithmetic means. From the values of the results (Skew), no statistically significant deviation of the asymmetry is observed in any of the variables, which means that the results are within the normal range. Analyzing the degree of curvature of the Gaussian curve, it can be concluded that the applied variables are distributed along the horizontal axis, and there are no statistically significant deviations from the normal values of the arithmetic means.

The normal distribution of the results obtained in both test batteries thus gives the right to apply further statistical processing methods.

The method of regression analysis is utilized to assess the impact of anthropometric dimensions towards the performance of motor duties. All anthropometric variables are treated as independent, or as predictors, while motor variables, each separately, as criterion. 
Table 2. Basic statistical motoric settings

\begin{tabular}{|c|c|c|c|c|c|c|c|}
\hline & $\mathrm{N}$ & Min & Max & Mean & Std. D. & Skew & Kurt \\
\hline MKVGJ & 37 & 2.00 & 2.73 & 2.31 & 0.17 & 0.275 & -0.476 \\
\hline MKVLART & 37 & 41.00 & 67.00 & 54.21 & 7.43 & 0.360 & -0.844 \\
\hline MHMBSH & 37 & 5.75 & 11.30 & 8.74 & 1.19 & -0.023 & 0.707 \\
\hline MHMBGJ & 37 & 4.5 & 7.95 & 5.95 & 0.76 & 0.668 & 0.645 \\
\hline MVR30M & 37 & 3.85 & 5.48 & 4.55 & 0.38 & -0.004 & -0.189 \\
\hline MVR60M & 37 & 7.43 & 9.77 & 8.29 & 0.57 & 0.415 & -0.370 \\
\hline MVR100M & 37 & 12.33 & 15.16 & 13.71 & 0.72 & 0.122 & -0.707 \\
\hline MTAPMK & 37 & 23 & 33 & 26 & 2.63 & 0.953 & 0.145 \\
\hline MTAPDOR & 37 & 36 & 48 & 40.75 & 3.85 & 0.515 & -0.700 \\
\hline MTETR & 37 & 10.9 & 14.97 & 12.93 & 1.00 & 0.159 & -0.41 \\
\hline MHAPAN & 37 & 7.57 & 11.36 & 9.46 & 1.02 & 0.060 & -1.012 \\
\hline MKATKEN & 37 & 8.14 & 11.3 & 9.87 & 0.77 & -0.224 & -0.394 \\
\hline MBLOKGO & 37 & 20 & 31 & 25.16 & 3.08 & 0.222 & -1.054 \\
\hline
\end{tabular}

Table 3. Basic coefficients of the regression analysis of the prediction variable system and criteria

\begin{tabular}{|c|c|c|c|c|}
\hline NO & VARIABLE & RO & DELTA & Q \\
\hline 1 & MKGJV & 0.67 & 0.36 & 0.00 \\
\hline 2 & MHMBGJ & 0.55 & 0.20 & 0.03 \\
\hline 3 & MVR3OM & 0.68 & 0.38 & 0.00 \\
\hline 4 & MTAPDOR & 0.53 & 0.17 & 0.05 \\
\hline 5 & MBLOKGO & 0.57 & 0.22 & 0.02 \\
\hline
\end{tabular}

Table 3 presents the main elements of regression analysis such as multiple correlation (RO), determination coefficient (DELTA) and validity (Q). From the given table we can conclude that the important impact of anthropometric variables in the performance of tasks is presented in 5 motor tests: MKVGJ, MHMBGJ, MVR30m, MTAPDOR, and MBLOKGOD. Meanwhile, with other tests, low levels of predicting system of anthropometric dimensions have been conducted towards the accomplishment of motor duties. The following tables present the reports of each motor variable with the predictive variable system. The results which were presented where those in which the anthropometric variables system as a whole have shown significant impacts on motor duty performance, while variables where the multiple correlation value was low, below the statistical significance level, they were not interpreted due to the fact that if the system of predictive variables in general does not realize significant correlation then the interpretation of the partial impacts is of no value. 
Table 4. presents the regression of the variable MKVGJ with the predictive anthropometric variables system, where we see that the system of these variables has shown significant statistical linkages. The value of the multiple correlation is $\mathrm{RO}=0.67$ while the percentage of the common variance explained is $36 \%$ and the significance level is 0.00 which this implies that the result in long jump test from the spot can be predicted with a fairly good accuracy based on the values of the aforementioned dimensions.

We see that AGJATKE and AGJATKR tests had the greatest partial impact on the realization of this task since the significance value of beta coefficients is 0.00 in both cases. This implies that the most successful individuals in carrying out MKVGJ test are the Karate competitors, who have more emphasis on the length of the leg and arm.

Table. 4. Regression of variable MKVGJ

\begin{tabular}{|c|c|c|c|c|c|c|c|c|}
\hline & B & $\begin{array}{c}\text { Std. } \\
\text { Error }\end{array}$ & Beta & $\mathrm{T}$ & Sig. & $\begin{array}{c}\text { Zero- } \\
\text { order }\end{array}$ & Partial & Part \\
\hline (Constant) & 0.64 & 0.87 & & 0.73 & 0.46 & & & \\
\hline APESHA & -0.00 & 0.00 & -0.32 & -1.92 & 0.06 & -0.16 & -0.32 & -0.25 \\
\hline ALART & 0.01 & 0.00 & 0.38 & 1.50 & 0.14 & 0.25 & 0.26 & 0.20 \\
\hline AGJATKE & 0.02 & 0.00 & 0.82 & 3.24 & 0.00 & 0.39 & 0.50 & 0.43 \\
\hline AGJASHP & -0.02 & 0.03 & -0.10 & -0.61 & 0.54 & 0.03 & -0.10 & -0.08 \\
\hline AGJAKR & -0.02 & 0.00 & -0.76 & -3.43 & 0.00 & 0.03 & -0.52 & -0.45 \\
\hline
\end{tabular}

$\mathrm{Ro}=0.67 ;$ Delta $=0.36 ; \mathrm{Q}=0.00$

Table 5 presents valid linkage of the MHMBGJ criterion with the predictor system, with the coefficient of multiple correlation $\mathrm{RO}=0.55$ which explains $20 \%$ of the common variability at the level of significance 0.03 . Although the system as a whole has achieved valid linkage in predicting the MHMBGJ motor test, none of the separate anthropometric components has shown to be a determinant of success in this test.

Table 5. Regression of variable MHMBGJ

\begin{tabular}{|c|c|c|c|c|c|c|c|c|}
\hline & B & $\begin{array}{c}\text { Std. } \\
\text { Error }\end{array}$ & Beta & $T$ & Sig. & $\begin{array}{c}\text { Zero- } \\
\text { order }\end{array}$ & Partial & Part \\
\hline (Constant) & -7.90 & 4.28 & & -1.84 & 0.07 & & & \\
\hline APESHA & 0.00 & 0.01 & 0.06 & 0.32 & 0.74 & 0.31 & 0.05 & 0.04 \\
\hline ALART & 0.06 & 0.04 & 0.47 & 1.65 & 0.10 & 0.55 & 0.28 & 0.24 \\
\hline AGJATKE & 0.01 & 0.04 & 0.07 & 0.25 & 0.80 & 0.39 & 0.04 & 0.03 \\
\hline AGJASHP & 0.03 & 0.15 & 0.03 & 0.21 & 0.83 & 0.34 & 0.03 & 0.03 \\
\hline AGJAKR & -0.00 & 0.04 & -0.03 & -0.13 & 0.03 & 0.34 & -0.02 & -0.02 \\
\hline
\end{tabular}


Table 6. presents the linkages of the variables MVR30m with the anthropometric variables system in which the level of valid statistical correlation is justified by the value of the multiple correlation $\mathrm{RO}=0.68$, which explains $38 \%$ of the common variability at the level of significance
0.00. This implies that Karate Competitors are most successful in carrying out the $30 \mathrm{~m}$ most successful running test that have more emphasis in arm length, as the significance value of beta coefficients is 0.03

Table 6. Regression of variable MVR30M

\begin{tabular}{|c|c|c|c|c|c|c|c|c|}
\hline & B & $\begin{array}{c}\text { Std. } \\
\text { Error }\end{array}$ & Beta & $T$ & Sig. & $\begin{array}{c}\text { Zero- } \\
\text { order }\end{array}$ & Partial & Part \\
\hline (Constant) & 4.40 & 1.90 & & 2.31 & 0.02 & & & \\
\hline APESHA & 0.00 & 0.00 & 0.16 & 1.03 & 0.30 & 0.21 & 0.18 & 0.13 \\
\hline ALART & 0.01 & 0.01 & 0.22 & 0.88 & 0.38 & -0.12 & 0.15 & 0.11 \\
\hline AGJATKE & -0.02 & 0.01 & -0.39 & -1.56 & 0.12 & -0.50 & -0.27 & -0.20 \\
\hline AGJASHP & 0.10 & 0.07 & 0.23 & 1.43 & 0.16 & 0.07 & 0.25 & 0.18 \\
\hline AGJAKR & -0.03 & 0.01 & -0.47 & -2.15 & 0.03 & -0.52 & -0.36 & -0.28 \\
\hline
\end{tabular}

$\mathrm{Ro}=0.68 ;$ Delta $=0.38 ; \mathrm{Q}=0.00$

Table 7, presents the validity of the predictor system which is also presented in the MTAPDOR motor variable, which has the multiple correlation coefficient $\mathrm{RO}=0.53$, which explains $17 \%$ of the common variability, at the significance level 0.05 the highest partial impact on realization of this task have had the AGJATKE and AGJATKR tests, since the significance value of beta coefficients is 0.01 and 0.05 in both cases. This implies that Karate Competitors are most successful in carrying out the most successful MTAPDOR test that has more emphasis in arm and leg length. Thus, we can conclude that for Karate competitors the dimension of the length of the extremities plays an important role towards producing speed in meeting with the objective. In our case, the distance between the two targets was the same for all competitors, while those competitors who had the dimension of the most prominent length achieved the best value. Based on this we can conclude that the length of the extremities plays an important role in the sport of karate by giving them a priority in the realization of the tests as well as in the situations of competing, particularly for karate competitors with more manifested dimensions.

Table 7. Regression of variable MTAPDOR

\begin{tabular}{|c|c|c|c|c|c|c|c|c|}
\hline & B & $\begin{array}{c}\text { Std. } \\
\text { Error }\end{array}$ & Beta & T & Sig. & $\begin{array}{c}\text { Zero- } \\
\text { order }\end{array}$ & Partial & Part \\
\hline (Constant) & -6.80 & 22.0 & & -0.30 & 0.75 & & & \\
\hline APESHA & -0.09 & 0.09 & -0.19 & -1.02 & 0.31 & -0.02 & -0.18 & -0.15 \\
\hline ALART & 0.25 & 0.20 & 0.35 & 1.20 & 0.23 & 0.29 & 0.21 & 0.18 \\
\hline AGJATKE & 0.44 & 0.22 & 0.59 & 2.03 & 0.05 & 0.31 & 0.34 & 0.30 \\
\hline AGJASHP & 0.30 & 0.81 & 0.07 & 0.37 & 0.70 & 0.18 & 0.06 & 0.05 \\
\hline AGJAKR & -0.53 & 0.20 & -0.65 & -2.56 & 0.01 & 0.02 & -0.41 & -0.38 \\
\hline
\end{tabular}

$\mathrm{Ro}=0.53$ 
Table 8. shows significant linkage between MBLOKGO criterion with prediction variable system with multiple correlation value $\mathrm{RO}=0.57$ that explains $22 \%$ common variability at the level of 0.02. AGJATKR test had the greatest partial impact on the realization of this task, since the significance value of beta coefficients is 0.01 , whilst the partial coefficients indicate the positive linkage of arm length linkage with the blow block test.

Table 8. Regression of variable MBLOKGO

\begin{tabular}{|c|c|c|c|c|c|c|c|c|}
\hline & B & $\begin{array}{c}\text { Std. } \\
\text { Error }\end{array}$ & Beta & T & Sig. & $\begin{array}{c}\text { Zero- } \\
\text { order }\end{array}$ & Partial & Part \\
\hline (Constant) & -0.36 & 17.0 & & -0.02 & 0.98 & & & \\
\hline APESHA & 0.05 & 0.07 & 0.12 & 0.69 & 0.49 & 0.22 & 0.12 & 0.10 \\
\hline ALART & 0.16 & 0.16 & 0.28 & 1.03 & 0.31 & 0.18 & 0.18 & 0.15 \\
\hline AGJATKE & 0.25 & 0.17 & 0.41 & 1.47 & 0.14 & 0.00 & 0.25 & 0.21 \\
\hline AGJASHP & 0.44 & 0.63 & 0.12 & 0.70 & 0.48 & 0.15 & 0.12 & 0.10 \\
\hline AGJAKR & -0.55 & 0.16 & -0.85 & -3.45 & 0.00 & -0.26 & -0.52 & -0.50 \\
\hline
\end{tabular}

\section{CONCLUSION}

Karate sport in Kosovo, with its mass and the success that karate athletes achieved internationally, belongs to the group of priority sports, which on the other hand creates an even greater obligation for its proper development. As one of the factors for achieving top results are of course the scientific research conducted with karate athletes. Based on these arguments, research has been conducted to determine the relationship between certain anthropometric measures and motor abilities relevant to karate sport. The research includes competitors from senior competition.

Applying regression analysis, relationships between anthropometric characteristics as predictors and certain motor abilities as criteria were determined. From the applied 13 variables for assessment of motor abilities, in 5 variables the prediction of the anthropometric variables was determined, as follows: 1. Running at $30 \mathrm{~m}$
(MVR30M), 2. Hand taping (MTAPDOR), 3. Impact block (MBLOKGO), 4. Long jump (MKGJV), 5. Throwing a medicine ball from lying (MHMBGJ).

Due to the fact that karate belongs to the group of polystructural acyclic sports, where the movements (blows) are of a ballistic nature, the explosive force of the lower and upper extremities as well as the frequency of movements are of great importance for performing effective movements. From this it can be concluded that the results obtained are logical and that the research has achieved its goal.

This type of research is always justified and very useful, especially for future researchers and trainers working in the training process. The results of such research enable future researchers in collaboration with coaches to invent new methods and models to improve the training process.

\section{REFERENCE}

1. Chaabčne, H., Franchini, E, Miarka, B., Amin, S. M., Mkaouer, B , Chamari, K. (2014). Time-motion analysis and physiological responses to karate offi cial combat sessions: is there a difference between winners and defeated karatekas, Human Kinetics Journals, Volume: 9 Issue: 2 Pages: 302-308

2. Berisha, A.,(2002), Variables of some physiological parameters before and after cargo loads. Unpublished masters thesis, University of Pristina.

3. Berisha, A., (2005), Variables of some physiological parameters before and after karate charge, Unpublished doctoral dissertation, University of Pristina. 
4. Fazliu, B., (2006), Relationships of anthropometric characteristics with karate techniques, Unpublished masters thesis, University of Pristina.

5. Kostovski, Ž., (1996), The influence of some anthropometric and motor variables on one kinematic parameter of the impact with a leg of the giant geri. First international gathering, Science in the Function of Sport, University of Skopje.

6. Kostovski, Ž. (2004). Measurement characteristics of some standard and specific motor tests apply to karate athletes of different chronological age, Doctoral dissertation, University of Skopje.

7. Shala, Sh., (2008), Longitudinal Relationship Factor three motor skills of Kosovo Karate.Unpublished masters thesis, University of Pristina.

8. Soklevska Ilievski, E., Shala, E., Kostovski, Z. (2018). Structure of situation motor stereotips of karate competitors and karate representatives, Sports Science \& Health, Vol. 8 Issue 1, pp12-18.

9. Zaborski, B., Šakiri, K., Đukanovic N, Kostovski, Ž., (2015), Changes in the physiological processes during traing and official competitions in young karate athletes. Sports Science \& Health, Vol. 5 Issue 2, p105-110. 6p.

Corresponding author:

Zarko Kostovski

University of SS Cyril and Methodius

Faculty of Physical Education Sport and Health

E-mail: zarkok@ukim.edu.mk 